\title{
Melatonin treatment of pigs with acute pancreatitis reduces inflammatory reaction of pancreatic tissue and enhances fitness score of pigs: experimental research
}

\author{
Katharina Grupp ${ }^{1 *} \mathbb{D}$, Johannes Erbes ${ }^{1}$, Annika Poppe ${ }^{2}$, Karin Wodack ${ }^{2}$, Andreas Gocht ${ }^{3}$, Constantin Trepte ${ }^{2}$,
} Jan Havel ${ }^{1}$, Oliver Mann ${ }^{1}$, Jakob R. Izbicki ${ }^{1}$ and Kai Bachmann ${ }^{1}$

\begin{abstract}
Background: Severe acute pancreatitis is associated with high morbidity and mortality. Melatonin is known as the activator of antioxidant enzymes. The main purpose of this study was to evaluate the clinical effect of melatonin treatment in a pig model with induced acute pancreatitis.

Methods: In this study, acute pancreatitis was induced in 38 German domestic pigs (German Hybrid). After induction of acute pancreatitis, 18 animals were treated with melatonin. Intraoperative clinical data, postoperative blood parameters, fitness, and Porcine Well-being (PWB) score, and post-mortal histopathological data were analyzed in both study groups.

Results: The matching procedure created two groups (melatonin group and control group) which were very similar. The fitness and PWB score were postoperative significantly enhanced in the melatonin group as compared to the control group ( $p=0.005$ and $p=0.003$ ). Additionally, histological analysis revealed that acinar necrosis, fat tissue necrosis, and edema were significantly reduced in the melatonin group as compared to the non-melatonin group ( $p=0.025, p=0.003$, and $p=0.028$ ).

Conclusions: Pigs, which were treated with melatonin, were characterized by higher fitness and PWB scores than those of the control group. Moreover, melatonin treatment reduces the acinar necrosis, fat tissue necrosis, and edema of pancreatic tissue. Thus, melatonin might be a useful therapeutic option in severe acute pancreatitis.
\end{abstract}

Keywords: Acute pancreatitis, Experimental model, Melatonin, Inflammation, Edema, Fitness score

\section{Introduction}

Acute pancreatitis is an inflammatory and potentially fatal disease [1]. The initial management of acute pancreatitis is supportive and includes optimization of electrolyte and fluid balance, providing adequate caloric support and preventing complications [2]. Local complications such as pancreatic necrosis, pancreatic pseudocysts, pancreatic duct injury, and peripancreatic vascular complications are treated by a combination of endoscopic, radiologic, and surgical techniques [2]. The surgical management for acute

\footnotetext{
* Correspondence: k.grupp@uke.de

${ }^{1}$ Department of General, Visceral and Thoracic Surgery, University Medical

Centre Hamburg-Eppendorf, Hamburg, Germany

Full list of author information is available at the end of the article
}

pancreatitis is indicated in case of acute gallstone pancreatitis or complications of acute pancreatitis [2]. Despite recent improving diagnostic and therapeutic options, acute pancreatitis is still associated with significant morbidity and mortality [1].

The hormone melatonin has been suggested to enhance the activation of antioxidant enzymes including superoxide dismutase, catalase, glutathione peroxidase, and glutathione reductase [3-5] and to reduce radical oxygen and nitrogen species [6-8]. In acute pancreatitis, melatonin has been described to play a protective role due to reduction of the gene expression and synthesis of proinflammatory cytokines such as tumor necrosis factor- $\alpha(\mathrm{TNF} \alpha)$ and proinflammatory interleukins such

(C) The Author(s). 2019 Open Access This article is distributed under the terms of the Creative Commons Attribution 4.0 International License (http://creativecommons.org/licenses/by/4.0/), which permits unrestricted use, distribution, and 
as interleukin (IL)-1 $\beta$, IL-6, IL-8, and prostaglandins [912]. In addition, melatonin has been shown to modulate the processes of apoptosis and necrosis [13-15]. Moreover, studies using animal models have shown that melatonin might play a protective role in acute pancreatitisassociated organ injuries [16-19]. The main purpose of this study was to further evaluate the clinical effect of melatonin treatment in pigs after induction of acute pancreatitis.

Our data demonstrate that melatonin treatment results in a reduction of acinar necrosis, fat tissue necrosis, and edema of pancreatic tissue during acute pancreatitis. Thus, it can be speculated that melatonin might be a useful therapeutic option in the treatment of severe acute pancreatitis.

\section{Methods}

\section{Animals}

The study was approved by the Governmental Commission on the Care and Use of Animals of the City of Hamburg. The animals received care in compliance with the "Guide for the Care and Use of Laboratory Animals" (NIH publication No. 86-23, revised 1996). Thirty-eight of 40 pigs (German Hybrid) were included. The animals were randomized to two different treatment groups: group 1 (melatonin, $n=$ 18) and group 2 (non-melatonin; control group; $n=20$ ). Two of the animals died before randomization.

Based on an $\alpha$ error of $5 \%$ and $\beta$ error of $20 \%$, the statistical calculation resulted in at least 18 animals per groups according to Fleiss tables. The animals were randomized online using a simple web-based randomization algorithm. Acute pancreatitis was induced in both groups, but only the animals of the melatonin group were treated with melatonin. The animals were randomized online using a simple web-based randomization algorithm. After the specific treatment, the postoperative course of the animals were not blinded. But the pathologist was blinded.

\section{Induction of anesthesia and monitoring}

The animals were randomized in two groups: group 1 (melatonin group; $n=18$ ), which were treated with melatonin after induction of acute necrotizing pancreatitis, and group 2 (non-melatonin group/control group; $n=20$ ). After fasting overnight with free access to water, ketamine (10 $\mathrm{mg} / \mathrm{kg})$, midazolam $(0.5 \mathrm{mg} / \mathrm{kg})$, azaperone $(4 \mathrm{mg} / \mathrm{kg})$, and atropine $(0.0015 \mathrm{mg} / \mathrm{kg})$ were administered for premedication. For monitoring of heart rate and oxygen saturation, a 5-lead electrocardiogram and pulse oximetry were used. After preoxygenation, anesthesia was induced by intravenous injection of $0.5 \mathrm{mg} / \mathrm{kg}$ midazolam. The animals were intubated and ventilated in a pressure-controlled mode assuring tidal volumes of $8-12 \mathrm{ml} / \mathrm{kg}$ and an end-expiratory pCO2 of $35-40 \mathrm{mmHg}$ using an inspiratory oxygen concentration of 0.35 (Zeus, Draeger Medical Systems,
Luebeck, Germany). Continuous infusion of fentanyl (0.05 $\mathrm{mg} / \mathrm{kg} / \mathrm{h}$ ) and sevoflurane (Fet 2.0) was used for balanced anesthesia. After cleaning, shaving, disinfection, and sterile draping, the femoral artery was cannulated using a $5 \mathrm{~F}$ thermistor-tipped arterial catheter (PICCO, PV 2015 L20, Pulsion, Germany)) for advanced hemodynamic monitoring. Two central venous catheters were surgically introduced into the internal and external jugular vein for volume administration and injection of cold indicator for transcardiopulmonary thermodilution using a PiCCOplus monitoring system (version 6.0, Pulsion Medical Systems, Munich, Germany). Fluid management was identical for all animals. A basal infusion rate of $13 \mathrm{ml} / \mathrm{kgBW} / \mathrm{h}$ was administered using hydroxyethyl starch 6\% 130/0.4 and Ringer's solution at a fixed ratio of 1:2. Macrocirculation was assessed continuously and maintained identically in all animals during the entire procedure according to an established algorithm for goal-directed fluid management [2022]. Body temperature was kept constant between 38 and $39^{\circ} \mathrm{C}$ using forced-air warming and a heating pad.

\section{Surgical procedures and induction of acute pancreatitis}

After repositioning of the pigs into supine position, a gastric tube has been placed and the abdomen was opened by a transverse upper laparotomy. A urinary catheter was placed directly into the bladder for urinary drainage. The pancreas and duodenum were mobilized and fixed at the laparotomy incision for intraoperative measurements. After dissection and cannulation of the main pancreatic duct (Vasofix 0.8 $\mathrm{mm}, \mathrm{B}$. Braun, Melsungen, Germany) between the pancreas and duodenal wall, a flexible polarographic measuring probe (CCP1, Licox, Kiel, Germany) for continuous measurement of the tissue oxygen tension (tpO2) was placed in the pancreatic head [23, 24]. After a few minutes of equilibration, the baseline values of all parameters (M0) were measured. According to the protocol, the measurements include blood samples, blood gas analysis and measurement of tissue oxygenation (tpO2) and the microcirculation in the pancreatic head with a laser Doppler imager (LDI, Moore, UK). Afterwards, acute necrotizing pancreatitis was introduced by intraductal infusion of glycodeoxycholic acid (GDOC, 10 mmol/l, pH 8, Sigma-Aldrich, St. Louis, MO, USA) over a period of $15 \mathrm{~min}$ as previously described, using an automated infusion system (Perfusor ${ }^{\circ} \mathrm{fm}$ (MFC), B Braun, Melsungen, Germany) to avoid pancreatic pressure necrosis [25]. This was paralleled by continuous intravenous infusion of cerulein at $5 \mu \mathrm{g} / \mathrm{kg} / \mathrm{h}$ (Sigma-Aldrich, St. Louis, MO, USA). The cannula has been removed, and the pancreatic duct was ligated. Sixty minutes (M1) and 120 min (M2) after completion of the intraductal infusion measurements were repeated. Directly after M2, the animals of group 1 (melatonin treatment) received a bolus of $10 \mathrm{mg} / \mathrm{kg}$ melatonin (Sigma-Aldrich, St. Louis, MO, USA) was applied via the central venous catheter. After the 
start of the therapy, a stabilization period of $30 \mathrm{~min}$ was allowed before the effects were measured every $60 \mathrm{~min}$ (M3-8). After the last intraoperative measurement (M8), all catheters were removed except the central venous catheter that was subcutaneously tunneled to the dorsal neck of the pig for application of analgesic medication and blood gas testing in the postoperative course. The abdominal cavity and incision of the neck have been closed, and anesthesia was terminated. The animals were extubated, and in case of sufficiently spontaneous breathing, they were transferred to heated boxes in the animal facility. For 7 days, the animals have been closely monitored and analgesics were given every 4-6h (piritamide $15 \mathrm{mg}$, equivalent to $10 \mathrm{mg}$ morphine). The animals were kept in small groups of 5-8 animals in a mulched stall in the animal facility with free access to straw and regular diet for pigs. They had a normal light-dark cycle via window. The animals had free access to straw and regular diet for pigs and water from the tap. All animals were checked by a veterinarian after arrival at the animal facility and then daily until death. No intervention was performed prior to the experiment.

Twenty-four hours prior to surgery, they were kept in a separate compartment. After fasting overnight with free access to water, they underwent premedication and anesthesia. Once a day, blood samples and blood gas analysis were performed and the animals were evaluated for their fitness using two scores (fitness and Porcine Well-being (PWB) score) that had been used earlier by our group [26, 27]. Animals surviving the observation period were re-anesthetized on the seventh postoperative day and sacrificed by fast injection of potassium chloride during anesthesia. The pancreas was removed for histopathologic examination and molecular biological analysis. In animals that died during the postoperative course, the pancreas was removed directly after detection of death.

\section{Histopathological analysis}

Representative specimens of the pancreas were taken. Parts of each pancreatic area, that is, head, corpus, and tail were stored in $3.5 \%$ buffered formalin, separately. The tissues were then processed and embedded in paraffin, and $5-\mu \mathrm{m}$ slices were stained with hematoxylin and eosin. The slices were examined by an experienced pathologist. Specimens were examined by a treatment-blinded experienced pathologist. The histopathologic evaluation of the pancreatic lesions was based on a previous publication [28]. Histopathologic changes were evaluated for each pancreatic area, that is, head, corpus, and tail, separately, and for each anatomic region, a total score ranging from 0 (no alterations) to 12 (severe pancreatitis) was determined (Fig. 3). Primary and secondary endpoints are overall survival, histopathological score, and postoperative fitness and well-being score.

\section{Statistical analysis}

Statistical analysis was performed with SPSS ${ }^{\circ}$ for Windows ${ }^{\circ}$ (Version 22.0) (SPSS Inc., Chicago, IL). A detectable difference of $25 \%$ versus $75 \%$ in survival was used to calculate group size. According to the randomization, the treatment group was evaluated versus the control group. Descriptive analysis of the parameters is expressed as median and range due to the low number of subjects per group.

For analysis of the difference between the groups in repeated measurements, the variance analysis for repeated measurements was used to evaluate the change within group, change between groups, and the interaction. The Bonferroni testing was used for post hoc analysis. The survival time was calculated using the log-rank test.

Significance statements refer to $p$ values of two-tailed tests that were less than 0.05 .

\section{Results}

\section{Baseline data of animals}

The animals were randomized according to the operative procedure into the following two groups: group 1/melatonin group and group 2/non-melatonin group. A total of 18 animals were treated with melatonin, while a total of 20 animals were randomized to the control group. The clinical characteristics of the pigs of the two groups were similar at baseline. In detail, the length was $100(92-108) \mathrm{cm}$ and weight was 30.7 (25.9-35.5) $\mathrm{kg}$ of the pigs of the melatonin group and $98.8(88-104) \mathrm{cm}$ and $30.3(26.8-35.1) \mathrm{kg}$ of the pigs of the non-melatonin group ( $p=0.526$ and $p=0.745)$.

\section{Overall survival of animals}

All of the pigs of the melatonin group survived the intraand postoperative course, whereas three pigs of the control group died. The overall survival rate showed no significant differences (mortality $0 \%$ vs. $15 \% ; p=0.23$ ). The survival time was similar in both groups of pigs $168 \mathrm{~h}(85 \%$ CI 168 $168)$ vs. 144 h (95\% CI 119-168) ( $p=0.092$; Fig. 1$).$

\section{Tissue oxygenation (tp $02 \mathrm{mmHg}$ ) of the pancreatic tissue}

Figure 2 shows the tissue oxygenation of the pancreas during the operative course. No differences were observed regarding the tissue oxygenation of the analyzed two groups. The repeated measurement analysis of variance revealed significant changes within the group $(p<$ $0.001)$ and no significant impact of the group $(p=0.398)$ or the interaction $(p=0.844)$.

Intraoperative hemodynamic data and chemical blood results All animals were kept in stable hemodynamic conditions during the operation. Additional files 1 and 2 show the hemodynamic data and the results of the blood tests (Additional files 1 and 2). These data demonstrate that there were no significant differences concerning the analyzed parameters between both analyzed animal cohorts. 


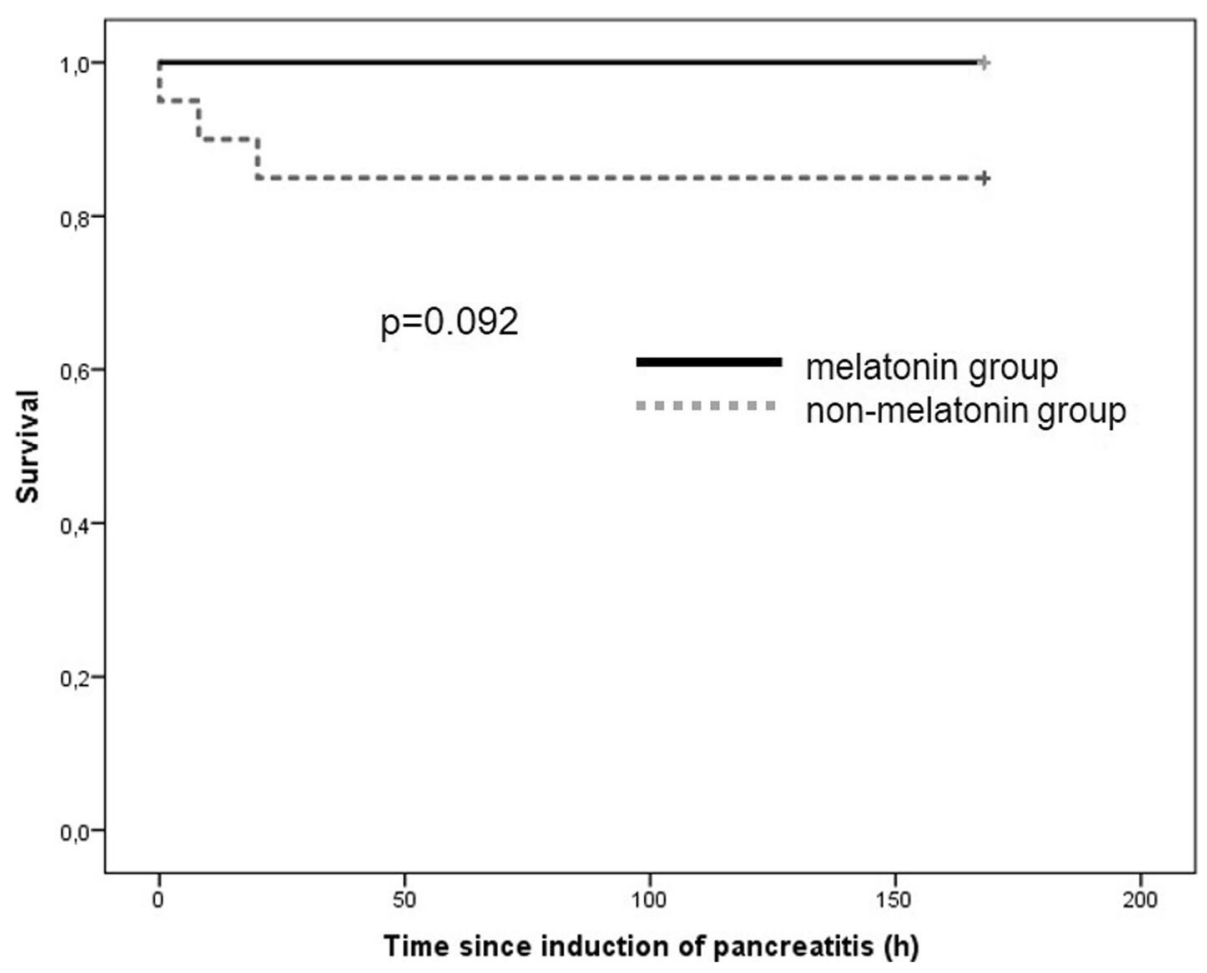

Fig. 1 Overall survival

\section{Postoperative fitness and PWB score}

As demonstrated in Table 1, pigs of the melatonin group were characterized by a higher fitness and PWB score as compared the pigs of the control group.
The repeated measurement analysis of variance revealed significant changes within the group for the postoperative fitness and the PWB score $(p=0.001$ and $p<0.001$ respectively). Post hoc analysis revealed significant advantage of the melantonin treatment for

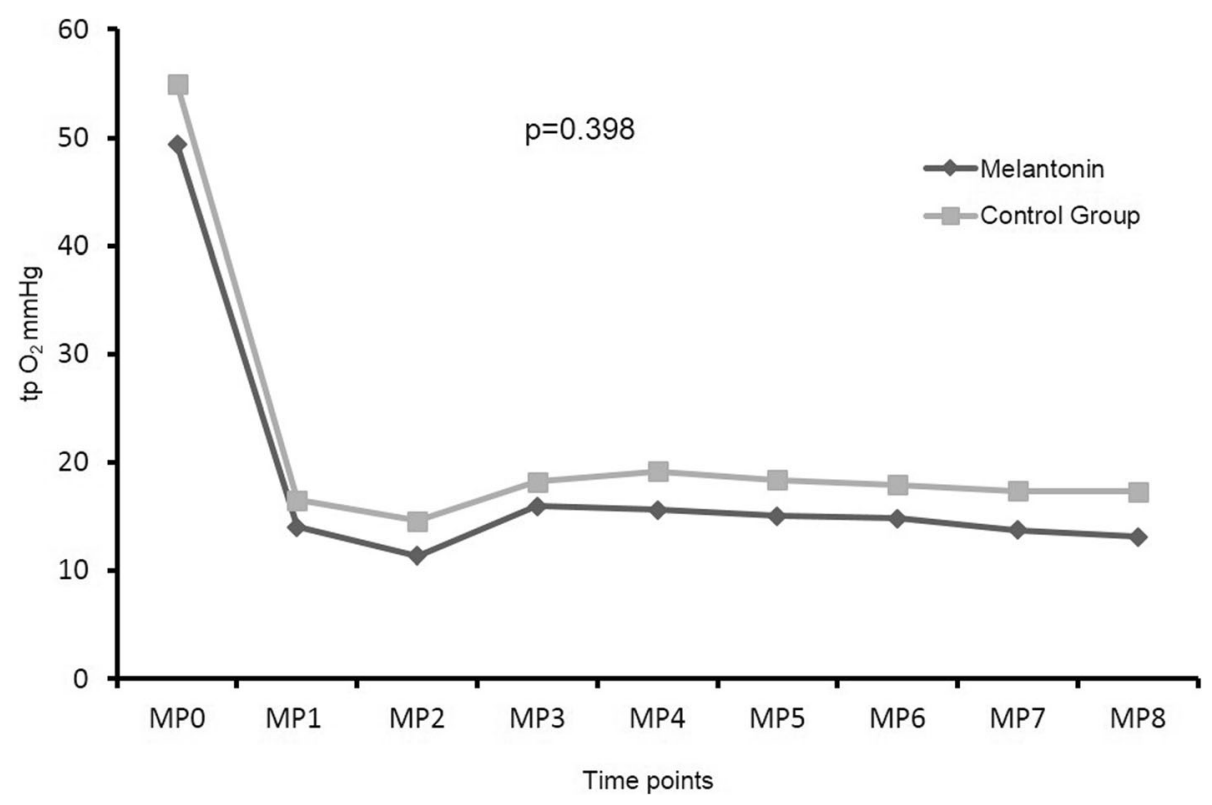

Fig. 2 Tissue oxygenation (tp $\mathrm{O} 2 \mathrm{mmHg}$ ) of the pancreas 
Table 1 Postoperative fitness and PWB score of the animals

\begin{tabular}{|c|c|c|c|c|c|c|c|}
\hline & \multicolumn{7}{|l|}{ Postoperative } \\
\hline & Day 1 & Day 2 & Day 3 & Day 4 & Day 5 & Day 6 & Day 7 \\
\hline \multicolumn{8}{|l|}{ Fitness score } \\
\hline Group 1 (melatonin) & $2(1-4)$ & $3(2-4)$ & $2(1-4)$ & $3(1-4)$ & $3(1-4)$ & $3(2-4)$ & $3.5(2-4)$ \\
\hline Group 2 (non-melantonin) & $2(0-3)$ & $2(0-3)$ & $2(0-4)$ & $2.5(0-4)$ & $3(0-4)$ & $3(0-4)$ & $3(0-4)$ \\
\hline$p$ & $p=0.793$ & $p=0.034$ & $p=0.959$ & $p=0.188$ & $p=0.013$ & $p=0.173$ & $p=0.003$ \\
\hline \multicolumn{8}{|l|}{ PWB score } \\
\hline Group 1 (melatonin) & $31.5(21 .-45)$ & $37(28-45)$ & $36(23-48)$ & $41.5(32-48)$ & $42.5(35-47)$ & $43(32-48)$ & $45.5(33-48)$ \\
\hline Group 2 (non-melantonin) & $31(0-39$ & $33.5(0-41)$ & $33(0-44)$ & $34(0-43)$ & $34.5(0-46)$ & $35(0-43$ & $33.5(0-42)$ \\
\hline$p$ & $p=0.689$ & $p=0.745$ & $p=0.256$ & $p=0.003$ & $p<0.001$ & $p=0.001$ & $p=0.003$ \\
\hline
\end{tabular}

both scores $(p=0.005$ and $p=0.003)$. The interaction was $p=0.069$ and 0.032 respectively.

\section{Histopathologic score for severe acute porcine pancreatitis}

The histopathological analysis revealed that acinar necrosis, fat tissue necrosis, and edema were significantly reduced in the melatonin group as compared to the non-melatonin group $(p=0.025, p=0.003$, and $p=0.028$; Table 2). Histological findings in normal pancreas (of pigs that died before randomization) and different stages of the pancreatitis are demonstrated in Fig. 3. All tissue sections were stained with hematoxylin-eosin.

\section{Discussion}

This study was undertaken to analyze the clinical effect of melatonin treatment in an animal model after induced acute pancreatitis. Our study shows that the fitness and PWB score were significantly higher in pigs which were treated with melatonin as compared to the control group. Moreover, melatonin treatment reduced acinar necrosis, fat tissue necrosis, and edema of the pancreatic tissue. Thus, it can be speculated that melatonin might be a useful therapeutic option in the treatment of severe acute pancreatitis.

The initial management of acute pancreatitis includes fluid replacement and optimization of electrolyte balance and providing adequate caloric support [2]. Surgical treatment is necessary in case of acute gallstone pancreatitis or of complications is present which need surgical management [2]. In general, a cholecystectomy is indicated for gallbladder stones or sludge [29]. If only sludge is present, the treatment with ursodeoxycholic acid can be started-as a long-term therapy [29]. An endoscopic biliary sphincterotomy should be performed in patients after cholecystectomy but with still present repeated attacks of pancreatitis with signs of a biliary origin or in patients with sphincter of Oddi dysfunction [29]. Local complications of acute pancreatitis such as pancreatic necrosis, pseudocyst formation, pancreatic duct disruption, and peripancreatic vascular injuries are treated by a combination of endoscopic, radiologic, and

Table 2 Histopathologic score for severe acute porcine pancreatitis

\begin{tabular}{|c|c|c|c|c|c|}
\hline & Acinar necrosis & Fatty tissue necrosis & $\begin{array}{l}\text { Intralobular inflammation (plasma cells, } \\
\text { lymphocytes, and granulocytes outside } \\
\text { parenchymal and fatty tissue necrosis) }\end{array}$ & Edema & Overall \\
\hline Melatonin group & $2.5(0.0-3.0)$ & $1.2(0.0-3.0)$ & $2.0(0.3-3.0)$ & $2.7(1.0-3.0)$ & $7.9(3.0-12.0)$ \\
\hline $\begin{array}{l}\text { Non-melatonin } \\
\text { group }\end{array}$ & $2.7(2.0-3.0)$ & $2.0(1.0-3.0)$ & $2.5(1.0-3.0)$ & $3.0(2.0-3.0)$ & $9.7(8.3-12.0)$ \\
\hline$P$ & $p=0.025$ & $p=0.003$ & $p=0.150$ & $p=0.028$ & $p=0.006$ \\
\hline Score & Acinar necrosis & $\begin{array}{l}\text { Fatty tissue necrosis } \\
\text { (in relation to plane) }\end{array}$ & $\begin{array}{l}\text { Intralobular Inflammation (plasma cells, } \\
\text { lymphocytes, and granulocytes outside } \\
\text { parenchymal and fatty tissue necrosis) }\end{array}$ & Edema & \\
\hline 0 & Nil & Nil & Nil & Nil & \\
\hline 1 & $<10$ acinar cell necrosis/lobule & $<1 / 3$ of plane & Loose infiltrates ( $\leq 30$ cells/HPF) & Interlobular edema & \\
\hline 2 & $\geq 10$ acinar cell necrosis/lobule & $\begin{array}{l}\geq 1 / 3 \text { to }<2 / 3 \\
\text { of plane }\end{array}$ & $\begin{array}{l}\text { Moderate infiltrates }(>30 ; \leq 100 \\
\text { cells/HPF) }\end{array}$ & $\begin{array}{l}\text { Interacinar edema, } \\
\geq 2 \text { lobules }\end{array}$ & \\
\hline 3 & $\geq 1 / 3$ of plane & $\geq 2 / 3$ of plane & Dense infiltrates (> 100 cells/HPF) & $\begin{array}{l}\text { Intercellular edema, } \\
\geq 2 \text { lobules }\end{array}$ & \\
\hline
\end{tabular}




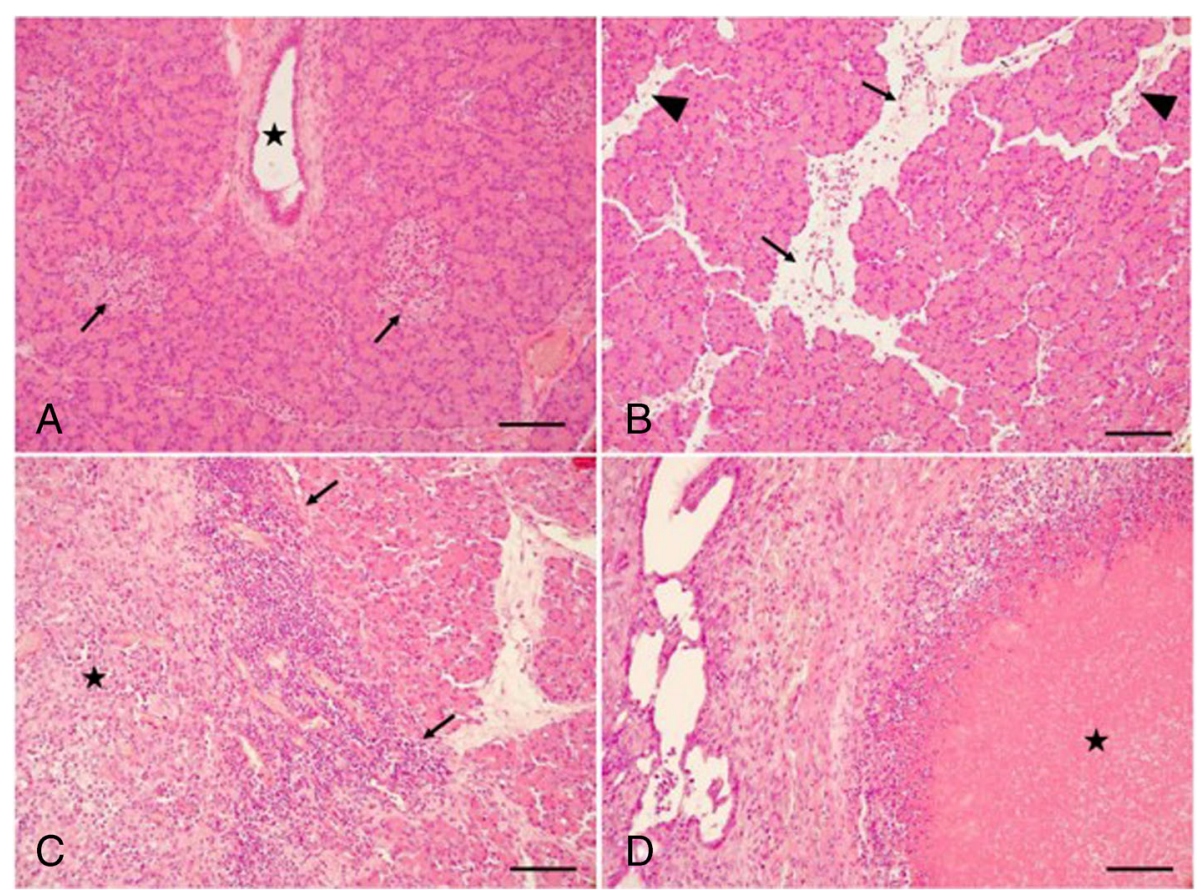

Fig. 3 Histological findings in normal and pancreatitis-induced pigs. All tissue sections were stained with hematoxylin-eosin. a Normal pancreas showing an intralobular pancreatic duct (star), acini and endocrine islets (arrows). b Mild disease with scattered inflammatory cells and interlobular edema (arrows) as well as interacinar edema (arrowheads). In this example, the total histopathological pancreatitis score was 3. c Moderate disease with dense inflammatory infiltrates intralobular (arrows) as well as focal tissue necrosis (star). In this example, the total histopathological pancreatitis score was 6. $\mathbf{d}$ Severe disease with extensive tissue necrosis (star) and dense inflammatory cells around the necrotic area. In this example, the total histopathological pancreatitis score was 11. All bars equal $50 \mu \mathrm{m}$

surgical techniques [2]. Despite recent advances in diagnostic and therapeutic options of acute pancreatitis, the acute pancreatitis is still associated with high morbidity and mortality [1].

Pathophysiologically, it is believed that trypsinogen activation [30, 31] and inflammatory signaling pathways such as NF- $\kappa \mathrm{B}$ signaling induce acinar cell damage and result in acute pancreatitis [32-34]. NF- $\kappa \mathrm{B}$ signaling is mediated by pathologic calcium overload and the activation of protein kinase $\mathrm{C}$ isoforms [32]. Initially, proinflammatory mediators stimulate $\mathrm{I} \kappa \mathrm{B}$ kinase resulting in the nuclear location of activated NF- $\kappa \mathrm{B}$ [32]. In the nucleus, NF- $\kappa \mathrm{B}$ binds to DNA response elements, resulting in the upregulation of proinflammatory cytokine [35]. These proinflammatory mediators, such as tumor necrosis factor- $\alpha$ and interleukin- 1 , activate the NF- $\kappa$ B signaling pathway in a positive feedback loop [32]. Moreover, the concentrations of cytokines and chemokines causing acinar cell damage increase [32]. In our study, the melatonin treatment reduced the acinar necrosis, fat tissue necrosis, and edema of pancreatic tissue during acute pancreatitis. Thus, it can be speculated that melatonininduced anti-inflammatory signaling cascades and suppresses the inflammatory pathways. This suggestion is underlined by earlier studies describing melatonin as an activator of antioxidant enzymes including the superoxide dismutase, catalase, glutathione peroxidase, and glutathione reductase [3-5]. Moreover, melatonin has been suggested to reduce radical oxygen and nitrogen species [6-8]. Furthermore, studies have demonstrated that melatonin plays a protective role due to suppression of the gene expression and synthesis of proinflammatory cytokines such as tumor necrosis factor- $\alpha$ and proinflammatory interleukins and prostaglandins [9-12].

Several other antioxidants have been reported in literature, and it has been suggested that increasing the circulating levels of certain antioxidants such as glutathione, $\mathrm{n}$-acetyl-cysteine, $\alpha$-lipoid acid, vitamin A, vitamin E, and vitamin $C$ helps to prevent the accumulation of free radicals inside our cells thus reducing oxidative stress [36-38]. For example, N-acetylcysteine (NAC), a thiol-containing synthetic compound used in the treatment of acetaminophen toxicity, has been analyzed in experimental hepatic ischemia-reperfusion (I/R) injury which occurs in both liver resection surgery and in transplantation [39]. While some authors described no positive findings [40-42], another study showed that NAC reversed the beneficial effects of ischemic preconditioning [43]. However, our study shows that another antioxidant melatonin reduces inflammatory reaction of 
pancreatic tissue and enhances fitness score of pigs with acute pancreatitis. Our findings are supported by an earlier study using melatonin in rats, and cells before the pancreatitis were induced [44]. Inositol-requiring $1 \alpha$ (IRE1 $\alpha)$-mediated Jun $\mathrm{N}$-terminal kinase (JNK)/nuclear factor-kappa B (NF-kB) pathway were activated early in AR42J cells and rat AP models [44]. Melatonin significantly inhibited the expression of proinflammatory cytokines and regulated apoptosis-related protein expression [44]. Furthermore, melatonin treatment resulted in reduced pancreatic tissue injury [44]. Thus, the authors suggested that melatonin treatment protects AR42J cells and Sprague-Dawley rats against AP-associated injury, probably through downregulation of IRE1 $\alpha$-mediated JNK/NF-кB pathways [44].

Next, we discuss the right time point of the beginning of the treatment with melatonin after the induction of acute pancreatitis. In our study, we used a short interval between the induction of the pancreatitis and the start of the melatonin treatment, since the direct intraductal injection of bile acid has been shown to induce acute pancreatitis within a few minutes-much faster as compared to gallstone-induced acute pancreatitis $[45,46]$. This assumption is underlined by the fact that we macroscopically observed acute severe pancreatitis prior to the beginning of our therapeutic intervention. Moreover, we choose a short interval since the effect of a clinical improvement of the pancreatic microcirculation might be reduced if fulminate necrosis of the pancreas is already present.

The limitations of this study must be noted. Although this is a clinically relevant experimental pig model, the exact mechanism of how the melatonin treatment increased fitness of the animals and changes histopathological results remains elusive. Further functional studies are necessary to fully understand the underlying mechanism of melatonin effect.

Interestingly, we demonstrated that the melatonin treatment increased the fitness and PWB score of the pigs. This observation might be due to the anti-inflammatory effects of melatonin, which in turn might result in enhanced physical performance of the animals.

\section{Conclusion}

The postoperative fitness and PWB score were significantly higher in the pigs of the melatonin group than in the control group. Moreover, melatonin treatment resulted in reduced acinar necrosis, fat tissue necrosis, and edema of pancreatic tissue. Thus, it can be speculated that melatonin might be a useful therapeutic option in acute pancreatitis.

\section{Additional files}

Additional file 1: Intraoperative hemodynamic data of the pigs. (XLSX $13 \mathrm{~kb})$
Additional file 2: Results of blood test of the animals. (XLSX $12 \mathrm{~kb}$ )

Abbreviations

I/R injury: Ischemia-reperfusion; IL: Interleukin; IRE1a: Inositol-requiring 1a; JNK: Jun N-terminal kinase; NAC: N-acetylcysteine; NF-kB: Nuclear factorkappa B; PWB: Porcine Well-being; TNFa: Tumor necrosis factor-a; tp O2 $\mathrm{mmHg}$ : Tissue oxygenation

\section{Acknowledgements}

Not applicable.

Disclosure information

Nothing to disclose.

Funding

This research did not receive any specific grant from funding agencies in the public, commercial, or not-for-profit sectors.

Availability of data and materials

Please contact author for data requests.

\section{Authors' contributions}

KG and AG contributed to the writing of the manuscript, data collection, and data analysis. JE and AP contributed to the data collection. KW and CT contributed to the data analysis and data collection. JH contributed to the data analysis. OM and JRI contributed to the writing of the manuscript and study design. KB contributed to the data analysis and collection, writing of the manuscript, and study design. All authors read and approved the final manuscript.

\section{Ethics approval and consent to participate}

The study was approved by the Governmental Commission on the Care and Use of Animals of the City of Hamburg. The animals received care in compliance with the "Guide for the Care and Use of Laboratory Animals" (NIH publication No. 86-23, revised 1996).

Consent for publication

Not applicable.

\section{Competing interests}

The authors declare that they have no competing interests.

\section{Publisher's Note}

Springer Nature remains neutral with regard to jurisdictional claims in published maps and institutional affiliations.

\section{Author details}

${ }^{1}$ Department of General, Visceral and Thoracic Surgery, University Medical Centre Hamburg-Eppendorf, Hamburg, Germany. ${ }^{2}$ Centre of Anesthesiology and Intensive Care Medicine, University Medical Centre Hamburg-Eppendorf, Hamburg, Germany. ${ }^{3}$ Institute of Anatomy and Experimental Morphology, University Medical Center Hamburg-Eppendorf, Hamburg, Germany.

Received: 20 February 2019 Accepted: 25 March 2019

Published online: 11 April 2019

\section{References}

1. Yadav D, Lowenfels AB. The epidemiology of pancreatitis and pancreatic cancer. Gastroenterology. 2013;144:1252-61. https://doi.org/10.1053/j.gastro. 2013.01.068.

2. Shah AP, Mourad MM, Bramhall SR. Acute pancreatitis: current perspectives on diagnosis and management. J Inflamm Res. 2018;11:77-85. https://doi. org/10.2147/JIR.S135751

3. Ochoa JJ, Díaz-Castro J, Kajarabille N, García C, Guisado IM, Teresa C de, Guisado R. Melatonin supplementation ameliorates oxidative stress and inflammatory signaling induced by strenuous exercise in adult human males. J Pineal Res 2011;51:373-380. doi:https://doi.org/10.1111/j.1600-079X. 2011.00899.x.

4. Tan D-X, Manchester LC, Terron MP, Flores $\sqcup$, Reiter RJ. One molecule, many derivatives: a never-ending interaction of melatonin with reactive 
oxygen and nitrogen species? J Pineal Res. 2007;42:28-42. https://doi.org/ 10.1111/j.1600-079X.2006.00407.X

5. Shagirtha K, Muthumani M, Prabu SM. Melatonin abrogates cadmium induced oxidative stress related neurotoxicity in rats. Eur Rev Med Pharmacol Sci. 2011;15:1039-50.

6. Lahiri S, Singh P, Singh S, Rasheed N, Palit G, Pant KK. Melatonin protects against experimental reflux esophagitis. J Pineal Res. 2009;46:207-13. https:// doi.org/10.1111/j.1600-079X.2008.00650.x

7. Peyrot F, Ducrocq C. Potential role of tryptophan derivatives in stress responses characterized by the generation of reactive oxygen and nitrogen species. J Pineal Res. 2008;45:235-46. https://doi.org/10.1111/j.1600-079X. 2008.00580.x

8. Reiter RJ, Paredes SD, Korkmaz A, Jou M-J, Tan D-X. Melatonin combats molecular terrorism at the mitochondrial level. Interdiscip Toxicol. 2008;1: 137-49. https://doi.org/10.2478/v10102-010-0030-2 .

9. Gülben K, Ozdemir H, Berberoğlu U, Mersin H, Yrkin F, Cakýr E, Aksaray S. Melatonin modulates the severity of taurocholate-induced acute pancreatitis in the rat. Dig Dis Sci. 2010;55:941-6. https://doi.org/10.1007/ s10620-009-0808-2.

10. Jung $\mathrm{KH}$, Hong S-W, Zheng H-M, Lee H-S, Lee H, Lee D-H, et al. Melatonin ameliorates cerulein-induced pancreatitis by the modulation of nuclear erythroid 2-related factor 2 and nuclear factor-kappaB in rats. J Pineal Res. 2010;48:239-50. https://doi.org/10.1111/j.1600-079X.2010.00748.x .

11. Chen H-M, Chen J-C, Ng C-J, Chiu D-F, Chen M-F. Melatonin reduces pancreatic prostaglandins production and protects against caeruleininduced pancreatitis in rats. J Pineal Res. 2006;40:34-9. https://doi.org/10. 1111/j.1600-079X.2005.00271.x

12. Sun $X-F$, Zhang H. NFKB and NFKBI polymorphisms in relation to susceptibility of tumour and other diseases. Histol Histopathol. 2007;22: 1387-98. https://doi.org/10.14670/HH-22.1387.

13. Muñoz-Casares FC, Padillo FJ, Briceño J, Collado JA, Muñoz-Castañeda JR, Ortega $R$, et al. Melatonin reduces apoptosis and necrosis induced by ischemia/reperfusion injury of the pancreas. J Pineal Res. 2006;40:195-203. https://doi.org/10.1111/j.1600-079X.2005.00291.X

14. Soybir G, Topuzlu C, Odabaş O, Dolay K, Bilir A, Köksoy F. The effects of melatonin on angiogenesis and wound healing. Surg Today. 2003;33:896901. https://doi.org/10.1007/s00595-003-2621-3.

15. Ganguly K, Sharma AV, Reiter RJ, Swarnakar S. Melatonin promotes angiogenesis during protection and healing of indomethacin-induced gastric ulcer: role of matrix metaloproteinase-2. J Pineal Res. 2010;49:130-40. https://doi.org/10.1111/j.1600-079X.2010.00776.x.

16. Alhan E, Kalyoncu NI, Kural BV, Erçin C. Effects of melatonin on acute necrotizing pancreatitis in rats. Z Gastroenterol. 2004;42:967-72. https://doi. org/10.1055/s-2004-813321

17. Ni Y, Wu J-s, Fang P-p, Wu X-I, Sun X-c, Jia G-b, Zhang R-z. Mechanism of liver injury in severe acute pancreatitis rats and role of melatonin. Zhonghua Yi Xue Za Zhi 2008;88:2867-2871.

18. Cöl C, Dinler K, Hasdemir O, Büyükaşik O, Buğdayci G, Terzi H. Exogenous melatonin treatment reduces hepatocyte damage in rats with experimental acute pancreatitis. J Hepatobiliary Pancreat Sci. 2010;17:682-7. https://doi. org/10.1007/s00534-010-0265-5

19. Huai J-P, X-c S, Chen M-J, Jin Y, Ye X-H, J-s W, Huang Z-M. Melatonin attenuates acute pancreatitis-associated lung injury in rats by modulating interleukin 22. World J Gastroenterol. 2012;18:5122-8. https://doi.org/10. 3748/wjg.v18.i36.5122

20. Kubitz JC, Annecke T, Forkl S, Kemming GI, Kronas N, Goetz AE, Reuter DA. Validation of pulse contour derived stroke volume variation during modifications of cardiac afterload. Br J Anaesth. 2007;98:591-7. https://doi. org/10.1093/bja/aem062

21. Kubitz JC, Forkl S, Annecke T, Kronas N, Goetz AE, Reuter DA. Systolic pressure variation and pulse pressure variation during modifications of arterial pressure. Intensive Care Med. 2008;34:1520-4. https://doi.org/10. 1007/s00134-008-1114-8

22. Reuter DA, Bayerlein J, Goepfert MSG, Weis FC, Kilger E, Lamm P, Goetz AE. Influence of tidal volume on left ventricular stroke volume variation measured by pulse contour analysis in mechanically ventilated patients. Intensive Care Med. 2003;29:476-80. https://doi.org/10.1007/s00134-003-1649-7 .

23. Lee SK, Morabito D, Hemphill JC, Erickson V, Holcroft JJ, Derugin N, et al. Small-volume resuscitation with $\mathrm{HBOC}-201$ : effects on cardiovascular parameters and brain tissue oxygen tension in an out-of-hospital model of hemorrhage in swine. Acad Emerg Med. 2002;9:969-76.
24. Boekstegers $P$, Weiss $M$. Tissue oxygen partial pressure distribution within the human skeletal muscle during hypercapnia. Adv Exp Med Biol. 1990;277:525-31.

25. Freitag M, Standl TG, Kleinhans H, Gottschalk A, Mann O, Rempf C, et al. Improvement of impaired microcirculation and tissue oxygenation by hemodilution with hydroxyethyl starch plus cell-free hemoglobin in acute porcine pancreatitis. Pancreatology. 2006;6:232-9. https://doi.org/10.1159/ 000091962

26. Toouli J, Brooke-Smith M, Bassi C, Carr-Locke D, Telford J, Freeny P, et al. Guidelines for the management of acute pancreatitis. J Gastroenterol Hepatol 2002;17 Suppl:S15-39.

27. Bloechle C, Emmermann A, Strate T, Scheurlen UJ, Schneider C, Achilles E, et al. Laparoscopic vs open repair of gastric perforation and abdominal lavage of associated peritonitis in pigs. Surg Endosc. 1998;12:212-8.

28. Wodack KH, Poppe AM, Tomkötter L, Lena T, Bachmann KA, Strobel CM, et al. Individualized early goal-directed therapy in systemic inflammation: is full utilization of preload reserve the optimal strategy? Crit Care Med. 2014;42: e741-51. https://doi.org/10.1097/CCM.0000000000000657 .

29. Testoni PA. Acute recurrent pancreatitis: etiopathogenesis, diagnosis and treatment. World J Gastroenterol. 2014;20:16891-901. https://doi.org/10. 3748/wjg.v20.145.16891

30. Gorelick FS, Thrower E. The acinar cell and early pancreatitis responses. Clin Gastroenterol Hepatol. 2009;7:S10-4. https://doi.org/10.1016/..cgh.2009.07.036 .

31. Saluja AK, Lerch MM, Phillips PA, Dudeja V. Why does pancreatic overstimulation cause pancreatitis? Annu Rev Physiol. 2007:69:249-69. https://doi.org/10.1146/annurev.physiol.69.031905.161253 .

32. Chen $Y$, Xie $C L$, Hu R, Shen $C Y$, Zeng $M$, Wu CQ, et al. Genetic polymorphisms: a novel perspective on acute pancreatitis. Gastroenterol Res Pract. 2017;2017:5135172. https://doi.org/10.1155/2017/5135172 .

33. Sah RP, Saluja A. Molecular mechanisms of pancreatic injury. Curr Opin Gastroenterol. 2011;27:444-51. https://doi.org/10.1097/MOG.0b013e328349e346.

34. Sah RP, Dawra RK, Saluja AK. New insights into the pathogenesis of pancreatitis. Curr Opin Gastroenterol. 2013;29:523-30. https://doi.org/10. 1097/MOG.0b013e328363e399

35. Singh P, Garg PK. Pathophysiological mechanisms in acute pancreatitis: current understanding. Indian J Gastroenterol. 2016;35:153-66. https://doi. org/10.1007/s12664-016-0647-y.

36. Clarkson PM, Thompson HS. Antioxidants: what role do they play in physical activity and health? Am J Clin Nutr. 2000;72:637S-46S. https://doi.org/10 1093/ajen/72.2.637S

37. Chan KM, Decker EA. Endogenous skeletal muscle antioxidants. Crit Rev Food Sci Nutr. 1994;34:403-26. https://doi.org/10.1080/10408399409527669

38. Sen CK, Packer L. Thiol homeostasis and supplements in physical exercise. Am J Clin Nutr. 2000;72:653S-69S. https://doi.org/10.1093/ajcn/72.2.653S

39. Jegatheeswaran S, Siriwardena AK. Experimental and clinical evidence for modification of hepatic ischaemia-reperfusion injury by $\mathrm{N}$-acetylcysteine during major liver surgery. HPB (Oxford). 2011;13:71-8. https://doi.org/10. 1111/j.1477-2574.2010.00263.x.

40. Baumann J, Ghosh S, Szakmany T, Jancso G, Ferencz A, Roth E, Bogar L. Short-term effects of $\mathrm{N}$-acetylcysteine and ischemic preconditioning in a canine model of hepatic ischemia-reperfusion injury. Eur Surg Res. 2008;41: 226-30. https://doi.org/10.1159/000135707

41. Montero EFS, Quireze C, d'Oliveira DMR. Bile duct exclusion from selective vascular inflow occlusion in rat liver: role of ischemic preconditioning and $\mathrm{N}$-acetylcysteine on hepatic reperfusion injury. Transplant Proc. 2005;37:4257. https://doi.org/10.1016/.transproceed.2004.12.194

42. Chavez-Cartaya R, Jamieson NV, Ramirez P, Marin J, Pino-Chavez G. Free radical scavengers to prevent reperfusion injury following warm liver ischemia. Transplant Proc. 1999;31:2439-40.

43. Rüdiger HA, Graf R, Clavien P-A. Sub-lethal oxidative stress triggers the protective effects of ischemic preconditioning in the mouse liver. J Hepatol. 2003:39:972-7.

44. Zhao Q, Tang X, Huang J, Li J, Chen Q, Sun Y, Wu J. Melatonin attenuates endoplasmic reticulum stress in acute pancreatitis. Pancreas. 2018;47:88491. https://doi.org/10.1097/MPA.0000000000001082.

45. Klar E, Schratt W, Foitzik T, Buhr H, Herfarth C, Messmer K. Impact of microcirculatory flow pattern changes on the development of acute edematous and necrotizing pancreatitis in rabbit pancreas. Digest Dis Sci. 1994;39:2639-44. https://doi.org/10.1007/BF02087702 .

46. Norman J. The role of cytokines in the pathogenesis of acute pancreatitis. Am J Surg. 1998;175:76-83. https://doi.org/10.1016/50002-9610(97)00240-7. 